\title{
Using Shared Workspaces in Higher Education
}

\author{
Klaas Sikkel ${ }^{(a)}$, Lisa Gommer ${ }^{(b)}$, and Jan van der Veen ${ }^{(b)}$ \\ (a) Faculty of Computer Science, University of Twente, \\ PO Box 217, 7500 AE Enschede, the Netherlands \\ sikkel@cs.utwente.nl \\ (b) DINKEL Institute, University of Twente \\ PO Box 217, 7500 AE Enschede, the Netherlands \\ \{E.M.Gommer, J.T.vanderVeen\}@dinkel.utwente.nl
}

\begin{abstract}
We evaluate the use of BSCW shared workspaces in higher education by means of a comparison of seven courses in which this environment was us ed.

We identify a number of different functions for which the BSCW environment has been used and discuss the relative success of these functions across the cases. In addition, we evaluate the cases with the 4E model of Collis et al. (2000) which predicts the chances of acceptance of ICT in an educational setting.

Effectiveness for the given task appears to be a prime success factor for using ICT. But an effective tool may fail due to other factors like ease of use and organisational, socialcultural or technological obstacles.

The particular strength of a shared workspace, for which BSCW is most effective and efficient, is providing a repository for objects of collaborative work. Other types of usage showed mixed results.

In the future we expect that learning takes place in an integrated, open ICT environment in which different kinds of tools are available for different purposes and users can switch between tools as appropriate. We could observe this in several of the case studies, where non-use of BSCW did not mean that a particular task was not performed, but, on the contrary, a more efficient solution for the same function was available. Shared workspaces have proven to be highly useful, but it seems advisable that their purpose be limited to what they were originally designed for.
\end{abstract}




\section{Introduction}

In Education, like in any sector, Information and Communication Technology (ICT) grows ever more important. There is a number of ways in which the use of technology can improve the quality of teaching and learning, or create a learning environment that could not exist otherwise. Virtual classrooms are a blessing in sparsely populated areas. Part-time students can save valuable travelling time through distance learning. Student working groups benefit from good ICT support for group work. In addition, the future professional should get acquainted with the tools of the trade, and for most professions these include a fair bit of ICT.

It is not the case, however, that the use of technology has a positive effect on education per se. Using ICT has some cost in terms of learning to work with a system, maintenance, and occasional disruption due to system failure. It possibly decreases flexibility and quality of interaction. There should be gains that offset the costs, in order to make it worthwhile.

Over the last years, we have witnessed a number of experiments with the use of ICT in higher education, ranging from very successful cases to outright failures. Apart from technical obstacles, it often happens that a technological infrastructure is offered but not adopted and used as wholeheartedly as intended by the course instructors. Not all students are keen to experiment with ICT for the sake of the experiment, when it is not effective for reaching the objectives of the course. The question, how to make effective use of ICT in education, is far from settled and merits further investigation.

The Internet as we know it today - where 'Web' and 'Internet' are synonyms for most people, and user-friendly browsers make its contents accessible to the population at large - came into existence around 1995 and has been subject to technological innovation ever since. We are still very much in the process of exploring how it can be used and what it can be used for. Educational experiences and insights take longer than five years to settle down into adequate teaching methods and a lot longer to affect the organisation of curricula and educational institutions.

We try out new techniques in all kinds of projects and we learn by doing. It is important to share the lessons learned, both positive and negative, so as to develop a common understanding of how we can use the new technology to our advantage. In this article we evaluate one particular technology - shared workspaces - that has been used for a number of different purposes in a range of different educational settings, within the University of Twente and elsewhere.

In a shared workspace a group of users can store documents and exchange information. This concept was implemented in an Internet-based tool called "Basic Support for Cooperative Work" (BSCW) (Bentley et al., 1995, 1997). It was originally designed for use by distributed research groups, but has been used extensively for educational purposes as well. The free distribution of the tool for academic purposes makes it attractive for experimenting with ICT, and the threshold to start using it was further lowered by a public server facility provided by GMD, the German National Institute for Information Technology, from which the tool originates.

A shared workspace is a very general tool that can be used for a lot of different purposes. This makes it a particularly interesting case for investigating how ICT can enhance educational facilities. It offers a novel kind of infrastructure, but it is not immediately clear what it can be used for and how it is optimally used. And indeed it has been used for a variety of different functions, with varying success.

In this article we investigate the use of BSCW in seven different cases. Four cases took place at the University of Twente. Three cases were taken from institutes for higher education elsewhere in Europe, so as to compensate for factors that are specific for Twente. We investigate which

functionalities were planned to be used and which ones were used in reality. Furthermore we try to determine variables that influence whether or not the offered BSCW support was used by the intended users. 
In Section 2 we give an overview of the technical functionality of the BSCW shared workspace system and the educational functions that can be supported. Section 3 describes the research methodology and introduces the 4E model. An extensive account of the seven cases is given in Section 4, followed by a cross-case comparison in Section 5 . Section 6 gives a further analysis and conclusions. 


\section{Basic Support for Cooperative Work}

After an overview of the most relevant technical functions of the BSCW Shared Workspace system we list the functions for which the system can be used.

\subsection{The BSCW Shared Workspace system}

BSCW is a groupware system, offering so-called shared workspaces. A shared workspace is a virtual space in which members of the workspace can store documents, messages, etc. A BSCW workspace is accessed with a conventional Web browser, but access is granted only to registered

\begin{tabular}{c|c|c|c|c|c|}
\hline BSCW & GMD FIT & \multicolumn{3}{c}{ ABOUT } & HELP \\
\hline ADD MEMBER & ADD DOC & ADD FOLDER & ADD URL & ADD MEETING & DISCUSSION \\
\hline SEARCH & & &
\end{tabular}

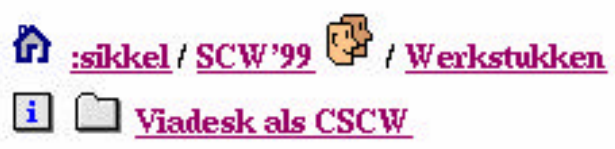

Het project van Remco Nijland, Joost van Bruijnsvoort en Niels Wensink

\begin{tabular}{|l|l|l|l|l|l|}
\hline$\square$ & Q \\
\hline
\end{tabular}

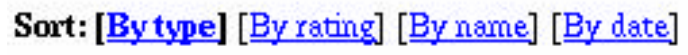
i] Final version.doc [0.2](joostvb) $1999-11-223 \mathrm{rating}(\mathrm{s})$ : g0od
[Modity] [Revise] [Set Lock] [
Definitieve verslag

1 i. Review Viacom door group h.doc ( Auke) $1999-10-27$

[Modify] [Replace] [Version] [Set Lock] [ Convert] [

1 回 國 Totaalverslag V3 (RemcoN) $1999-10-25$

[Modity] [Replace] [Version] [Set Lock] [Convert] [Add Note]

De te reviewen versie

1 i 通 011199-Review 'Analyse Viadesk.com' door groep G.doc (verberme) 1999-11-02

[Modify] [Replace] [Version] [Set Lock] [ Convert] [Add Note]

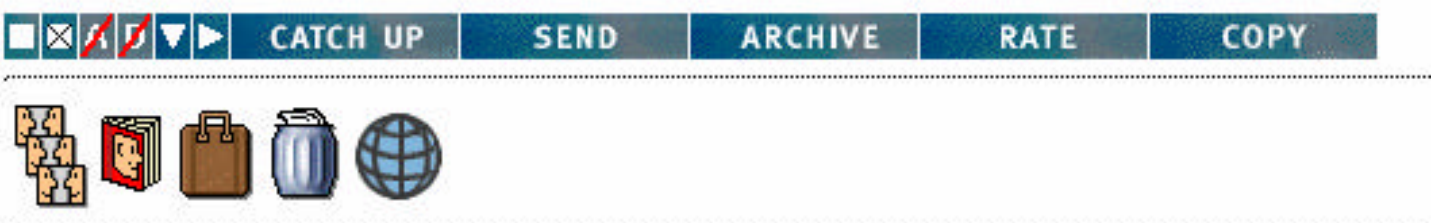

You are: 1 sikkel (Expert) [Edit Prets]

ECH [1] I905-1990 GMD

Figure 1: a typical shared workspace folder 
members of the workspace. Inside, the workspace is organized as a conventional folder structure. A typical BSCW folder (from actual use in a course) is shown in Figure 1.

The central functionality of a workspace is to provide a document storage facility. It can be accessed by its members independent of location, from anywhere in the internet, which makes it particularly suited for collaborative work in groups that do not meet face to face very often. Convenient additional features include

- Basic version management. A document history can be maintained as a sequence of versions.

- Locking. To prevent unintended simultaneous editing, documents can be locked.

- Awareness information. Icons attached to documents and lists of recent events allow the user to get an overview of what has happened in the workspace. Also it is possible to receive notification of certain types of events by email.

A workspace can handle documents of all kinds (text, images, audio, etc; any standard or nonstandard MIME type), but a user group should make sure that it uses a document format that is available to every person in the group (e.g. MS-Word).

Other objects that can be stored in a workspace include

- Notes, attached to documents or as separate entities. Notes can be replied to by other group members, providing a mechanism for structured discussions.

- Links to Web pages outside the workspace.

A complete description of its features can be found on the BSCW web site (http://bscw.gmd.de). One of the things that BSCW does not offer is clear guidelines of how to organize a workspace. In a way this is an asset: because it does not impose a structure, it is a general tool which can be used for a variety of different purposes (in fact the system was not developed with higher education as its intended application domain). Yet it is not self-evident what a good workspace organisation is and it takes some tuning to optimize it for a particular course.

The BSCW system originates from GMD, the German National Research Institute for Information technology. It was developed as a research prototype for an internet-based groupware system, first released in 1995 (Bentley et al., 1995). A completely restyled and restructured version was released in 1996 (Bentley et al., 1997). Later versions have added a number of features but the core functionality and user interface has not changed since then. So it is one of the older Webbased systems around. These days similar functionality is offered by commercial systems, like Xerox DocuShare (docushare.xerox.com) with a more professional look and feel - and with a different price tag.

BSCW has acquired popularity among institutions for higher education because of its low costs (free for non-commercial institutions) and high accessibility. This makes it particularly suitable for experimenting with ICT.

\subsection{Using shared workspaces}

The functionality of any system can be described at different levels. The technical functionality outlined above tells what you can do with a system in terms of features offered by the system. The domain functionality describes the types of functions the system can be used for in the application domain, in this case the educational domain. In this section and throughout the remainder of the paper, functions of the system are to be understood as educational functions, unless explicitly stated otherwise.

We list a number of different functions, all of which are known to have been used in higher education. Each function is illustrated with one or more examples.

a. Archiving. The shared workspace is used as a group archive.

Example: a project group is working on a product and uses BSCW to store their drafts, documentation and work planning documents.

This is the most obvious application of a shared workspace. 
Having all the information online allows more interaction between the students. Written comments on each other's contributions and threaded discussions are feasible with the system. This is expressed in the following functions:

\section{b. Collaborative authoring.}

Example: Students are writing a paper in a group. The paper is stored in a workspace accessible to all the group members and everyone can add their part and revisions. Locking and versioning are technical functions that specifically support collaborative authoring.

c. Discussion.

Example: Every week, a statement is put into the workspace by the teacher and students react on the statement and on each other's contributions.

Technically this is supported by the threaded discussion feature of BSCW.

d. Reviewing. Commenting on each other's work, assessment or peer review.

Example 1: Students have to write an article on a certain topic and during the following week, they have to comment on the work of their peers. During the lessons, the articles and comments are used as a starting point for discussion.

Example 2: Students hand in their work into their personal workspace. The teacher gives feedback by adding commentary notes to the assignments.

Reviewing can be realized with the general workspace facilities. Figure 1 in fact shows a folder with a draft paper, two reviews by peer groups, and a final version based on the reviews.

Related to reviewing, BSCW has a technical facility for rating documents by workspace users, but this was not used in these two examples.

Having the students' work online implies that the instructors have more insight in how the students perform their tasks:

e. Monitoring. The teacher monitors the students' activities.

Example 1: during a project, the tutor of a project group has access to their workspace to see how work is progressing, how the different project members are contributing and how much activity there is in the group.

Example 2: the course instructor gets daily notification emails from the BSCW server listing all events in the students' workspaces. These are collected for subsequent statistical analysis.

The awareness facilities allow a rough overview at a glance of what happens in a workspace, for monitoring a particular group, as in Example 1. For an in-depth statistical analysis it is possible to mine the BSCW server logs, but this requires additional work. Most of the salient statistics can be derived from the notification emails, if so required.

Various types of communication are supported by BSCW. It does not have to replace email, but can be used in combination with it.

f. Communication. Exchange of messages for work planning, feedback, etc.

Example 1: Students put their assignments in a workspace folder, and the teacher gives feedback by adding notes to the students' folders.

Example 2: Instead of using e-mail, a project group uses BSCW to schedule meetings, distribute agendas and minutes, communicate about work progress, etc.

BSCW has a facility for meeting scheduling. Participants invited for a meeting receive email with a request to acknowledge or cancel their presence at the meeting.

In some courses getting experience in ICT is one of the objectives of the course:

g. Using ICT.

Example: In a teacher training course, students work with BSCW to experience how ICT can be used in education and to get ideas about using ICT in their own courses. 
Finally, there are a number of different functions, discovered by instructors who used BSCW, but not directly related to its core functionality. The list is not exhaustive, but only mentions functions that we know have been used.

h. Logistics.

Example 1: In a course, students have to hand in assignments to different teachers.

Assignments are placed in a central folder, so each teacher can select the assignment she has to assess.

Example 2: Student groups may choose among different assignments, but no two groups

may choose the same one. If two groups want to opt for the same assignment, it goes to the group which was the first to put a claim in the appropriate workspace folder.

The second example exploits the fact that all actions in a workspace are time-stamped.

i. Course info. BSCW is used to disseminate information on the course, exercises, etc.

Example: A shared workspace folder contains information about the tasks to be carried out.

Thus the information can be adapted as necessary during the course.

This is not a function for which BSCW is needed; the same material could be put on a web page (or distributed on paper). Reasons to use BSCW could be that the instructor did not have easy access to a web server or that it is convenient to put this information and the students' contributions in the same environment.

j. Access control.

Because a workspace is password-protected it provides a simple way to put resources on the Web without making them accessible to the entire internet. Furthermore, access to documents and folders can be restricted to particular subgroups.

Example 1: The teacher makes copyrighted background material (which he cannot put on a public web site) available in a workspace - the electronic equivalent of collection of articles which students can read in the library.

Example 2: Students make a portfolio, presenting their skills and experiences. They may not want to present this publicly on the internet.

Example 3: In a course where students have to hand in assignments, BSCW is used as an access mechanism. When a student has handed in his or her assignment, and it is graded by the teacher, the student gets access to the work of fellow students, by making him a member of a particular user group.

The last example involves some manual action of the course instructors. In one course (not in this survey) the BSCW environment has been extended to further support this type of use (van der Veen et al., 2000) 


\section{The evaluation framework}

The success of the educational functions described above was investigated in a series of case studies, described in Section 4. In addition, we evaluate the cases in the so-called 4E model (Collis, Peters and Pals, 2000) that predicts, on an abstract level, the chances of ICT being accepted in an educational setting In this section we introduce the evaluation framework.

\subsection{Methodology}

The investigation of the case studies is of a qualitative nature (although quantitative methods have been used in the evaluation of several cases). The purpose of this study is not to obtain statistically significant results, but to investigate possible reasons for success or failure of using shared workspaces in higher education. The case studies were selected because they cover a wide range of different educational activities. By analysing and comparing the different case studies, our goal is to understand why the use of BSCW in education has been successful in some settings and rather unsuccessful in others.

The qualitative nature of this investigation has some implications for the generalization of the findings (Yin, 1994). Our findings could be validated by further empirical research. Yet, in order to do such research, one should be able to make an educated guess of what the indicators for success and failure are. In this study we uncover possible indicators by analysing a range of different cases.

In 1999 an extensive evaluation of the use of BSCW at the University of Twente was carried out (Gommer, 1999), covering all educational settings in which the system had been used at this university in the past two years. In order to gather data for the case studies in this evaluation research, several methods were used. First of all, structured 1.5-hour interviews with teachers and instructors using BSCW in their courses were taken. An interview scheme was used with questions about subjects like the amount of training needed, support, functionalities and appreciation of BSCW. In several of these courses, data were obtained from students and course participants by means of questionnaires. These questionnaires contained both open and multiple choice questions and dealt with subjects like frequency of use, learning curve, functionalities, support, appreciation and technical problems.

From the eleven cases described in the evaluation, four were selected for this study. Three of these took place at the University of Twente (UT), one was conducted by UT staff at the Noordelijke Hogeschool at Leeuwarden, a university of professional education*. These particular four cases were selected because they differed most from each other in the way in which BSCW was used, the type of users and the extent to which the system was used successfully. Two of these were rather successful, the two other ones are relative failures.

In addition to these cases, we selected three cases from other institutes of higher education, to compensate for the specific setting of the University of Twente. The UT is a rather technology minded university with the ambition to maintain a high profile in the usage of ICT. Students and teachers are used to working with the internet, email, etc., for educational and other purposes. In such a setting, new technologies supporting education are more easily adopted.

The selection criterion we used to select the external cases, was the amount of detailed information we could find about these cases. We needed sufficient information about the educational setting, the target group, the extent to which BSCW was a success, and the interpretation of the case study in terms of our evaluation model.

\footnotetext{
* Universities of Professional Education ("Hogescholen") in the Netherlands, like "Fachhochschulen" in Germany, are distinct from regular universities and offer a degree comparable to Bachelor.
} 
To cast a given case study ex post into an evaluation model necessitates a certain amount of reinterpretation of the data. In order to prevent any possible misinterpretation, the resulting case descriptions, both within and outside the university, have been discussed with the instructors of these courses.

\subsection{The 4E model}

In the 4E-model of Collis et al $(1999,2000$, in press) a large number of variables for predicting the success of an ICT application in an educational setting are grouped into 4 general factors

- Educational effectiveness

- Ease of use

- Personal engagement

- Environmental variables, related to organisational, social-cultural and technological factors

These factors are further elaborated in Table 1. In order to get ICT accepted, the value of the system for the users must be above a certain threshold, otherwise the systems will be ignored. The latest version of the 4E model (Collis, Peters and Pals, 2000; in press) proposes a fixed threshold and an overall value that is the sum of the values of the 4 factors. This is illustrated in Figure 2.

\begin{tabular}{|l|l|}
\hline $\begin{array}{l}\text { Educational } \\
\text { effectiveness }\end{array}$ & $\begin{array}{l}\text { The relevancy for educational tasks depends on whether or not some of the } \\
\text { group's problems have been solved. For instance bridging distances between } \\
\text { group members or overcoming the lack of opportunities to meet each other face } \\
\text { to face. } \\
\text { The users' perception will be influenced by the relative advantages one gains } \\
\text { from using BSCW compared to other modes of accomplishing educational tasks. } \\
\text { These other modes can be face to face meetings or alternative telematic support } \\
\text { options. }\end{array}$ \\
\hline Ease of use & $\begin{array}{l}\text { Relevant "ease of use" tool characteristics include learnability, a friendly user } \\
\text { interface, and efficient ways of executing tasks that fit with usual working habits. } \\
\text { The perceived ease of use also depends on the user's computer skills, prior } \\
\text { experience with similar tools, convenient access to networked computers, } \\
\text { availability of support, and costs that come with using the telematic service. }\end{array}$ \\
\hline Engagement & $\begin{array}{l}\text { Personal feelings related to use of telematics. Pioneers are known to have a high } \\
\text { personal engagement in willing to invest additional effort in getting started and } \\
\text { using telematic services for education. They also perceive higher satisfaction } \\
\text { with successful use. On the other side, a lack of confidence in one's personal } \\
\text { skills to handle ICT results in a negative engagement. }\end{array}$ \\
\hline Environment & $\begin{array}{l}\text { Environmental factors are external to the course. They include organisational, } \\
\text { social-cultural and technological factors such as the attitude of individuals and of } \\
\text { the organisation towards technology related innovations for educational } \\
\text { purposes; the readiness of the organisation to offer telematic services and } \\
\text { support in an accessible, reliable and affordable way. }\end{array}$ \\
\hline
\end{tabular}

Table 1: The factors of the 4E-model 


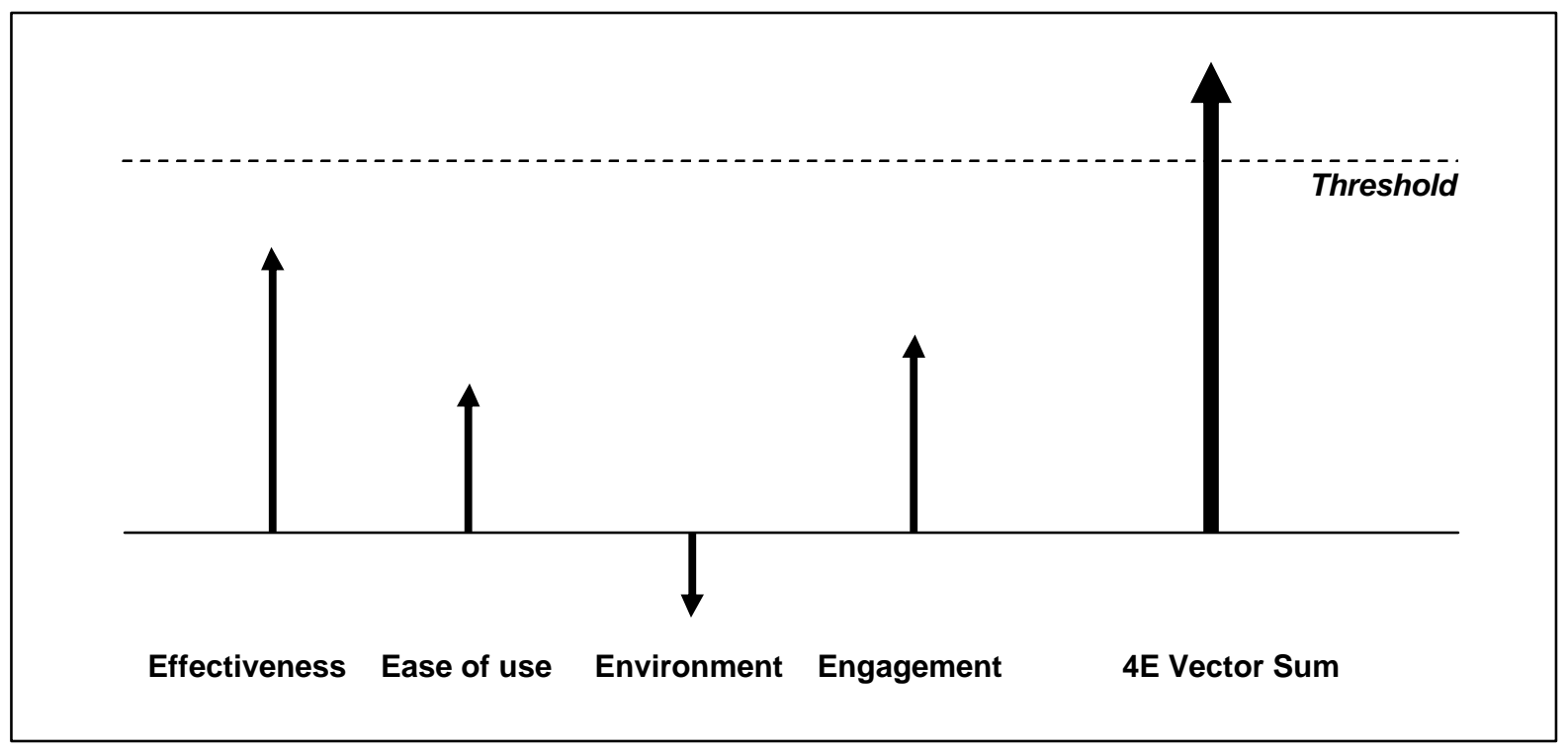

Figure 2: A system is accepted if the sum vector passes a certain threshold

All the case studies in section 4 are described in terms of educational functions and also evaluated in the 4E model. It seems reasonable to expect that the acceptance of (particular functions of) BSCW can be related to an assessment in terms of the 4E model. In particular, for functions that meet with varying degrees of acceptance, these ought to be correlated to different 4E assessments. 


\section{Case studies}

We describe seven case studies of BSCW usage. Three have taken place at the University of Twente at different faculties, three in other places in the Netherlands (one of which was organized by the University of Twente), one in the UK. The selection of this cases was discussed in Section 3 . In all cases, the use of several different functions was planned. Sometimes all functions were realized, but mostly the deployment of shared workspaces was only partially successful.

All cases studies are presented in the same format. We describe the course and the use of shared workspace functions intended to be used, followed by an evaluation of how BSCW was really used during the course. Subsequently, we analyze the case in terms of the $4 \mathrm{E}$ model. For the sake of easy reference, each case is labelled with a short name.

\subsection{Case 1: "Educational Training"}

Teacher training course, University of Twente, 1998/99 (Gommer 1999)

For new teaching staff of the university, an intensive course is given, where the new teachers learn the didactic skills needed for preparing, teaching and evaluating their courses. Once every two weeks, course participants meet at the educational centre of the university for lectures, active sessions, group work, etc. In between course days, groups of course members meet (live or virtually) to work on group assignments.

In order to let the new university teachers experience the use of ICT in education, several ICTtools are used in this course; a website, e-mail, BSCW, and computer assisted learning. The course website was used to supply the course members with information about assignments and activities. E-mail was used for communication between course members and instructors.

BSCW was introduced in this course as a support for making the group assignments. Also, every course member had a personal folder (portfolio) in BSCW where all course assignments and projects were stored. The course instructors put their personal feedback to every course participant in this portfolio. Also the progress of the course members was monitored by the instructors in BSCW. During the first weeks of the course, discussions about educational topics (e.g. about teaching strategies) were started in BSCW by the instructors.

The course workspace contained material that the instructors would not have put on a public website. The password protection of the workspace allowed to have this information online.

At the first course-day, all participants attended a computer practical where the website and BSCW were explained. During the practical, an instruction manual with assignments to practice with the functionalities of BSCW was given to them.

Intended use: archiving, collaborative authoring, discussion, reviewing, monitoring, communication, using ICT, course info, access control

Once the course started, BSCW was used by all the course members except one who insisted on using e-mail. BSCW was mainly used as a central place for handing in and storing assignments and reports. The discussions started, but quickly faded away after some course members tried it. Also, group assignments were not done in BSCW by most groups. The groups met face to face to divide tasks and exchanged files and communicated about work planning by using e-mail. Only the final products were put in BSCW for assessment and feedback from the instructors.

The course coordinators used BSCW for progress monitoring, to see how the course members were doing and if everyone was still on schedule. They complained however, about this task being difficult because of the folder-structure. Instructors sometimes failed to give timely feedback on assignments put in the workspace, because they were not aware that is had been handed in. This induced participants to send in assignments by email. In the following year (1999/2000, not evaluated in this study) the problem was successfully addressed by using email notification of workspace events. 
All group members experienced the use of groupware and some even indicated getting ideas for implementing groupware into their own courses.

Realized use: archiving, reviewing, monitoring, using ICT, course info, access control not realized: collaborative authoring, discussion, communication

Effectiveness: mostly negative. Perceived as effective for handing in assignments, because this was compulsory. Perceived as very ineffective for collaboration, because of live contact and e-mail. Also perceived as ineffective for communication compared to e-mail.

Ease of use: neutral. Participants are relatively experienced computer users, but unfamiliar with this interface. The system was not perceived as very user-friendly. All participants do have easy access to a networked computer.

Engagement: neutral. The users were relatively experienced computer users but there was not much experience in using ICT in education.

Environment: positive. Organization with a very positive attitude towards ICT and good facilities and infrastructure.

\subsection{Case 2: "Design Project"}

Multidisciplinary design project, University of Twente, 1998/99 (Gommer 1999)

The multidisciplinary design project is a course in which students from different faculties of the University of Twente take part. Major goals of the course are to get experience in working in multidisciplinary teams on non-trivial problems. Open problems that need solving are acquired from companies or institutions outside the university. These are addressed by teams of 5-8 students from different faculties. Students spend 240 hours on this project. Teams are coached by a teacher but otherwise operate autonomously.

A demo of BSCW was given at the starting session of this course, and students were offered the opportunity to use it. No further support was given other than a 4-page overview of the most important functionality. It was up to the groups whether they liked to use it.

Evaluation was done by means of a questionnaire about BSCW usage and satisfaction, included in the course evaluation form.

Intended use: archiving, collaborative authoring, communication

The evaluation results showed that most project groups used BSCW for archiving and cooperation. Some groups used their own solution, for example an FTP-server.

Communication was done through BSCW by only half the project groups. The other groups preferred e-mail.

Realized use: archiving, collaborative authoring

partially realized: communication

Effectiveness: positive. Students from different faculties (distance) and different time schedules. The tool was well suited for the type of work (project work)

Ease of use: positive. Participants are relatively experienced computer users. System was perceived as easy to learn. Participants have easy access to networked computer.

Engagement: positive. Relatively experienced computer users, willing to try out new technologies.

Environment: positive. Organization with a very positive attitude towards ICT and good facilities and infrastructure.

\subsection{Case 3: "CSCW course"}

Course on computer-supported cooperative work, University of Twente, 1998/99 (Gommer 1999)

In the Faculty of Computer Science BSCW was used in a course on Computer-Supported Cooperative Work. A substantial part of the course consists of exploring a particular sub-field in 
groups of 3-4 students. Each group had to submit a preliminary report which was reviewed by two peer groups. These reviews were to be taken into account in the writing of a final report.

A shared workspace had to be used for exchanging reports and reviews. Whether it was used for collaborative authoring and archiving was up to the groups.

In addition, BSCW was used as a logistic tool. All groups should take a different theme from a given list of possible subjects. If two groups wanted the same theme, it was assigned to the group which first claimed it in the workspace.

Intended use: archiving, collaborative authoring, reviewing, using ICT, logistics

Use of BSCW for peer review and logistics was successful. Also, because groupware was the subject matter of the course, finding out the advantages and the disadvantages of the system was an intended and realized aim.

Only a few groups used the system for collaborative authoring, however; most groups uploaded their work when a paper was due. This is not surprising, as most groups saw each other regularly face to face.

Realized use: archiving, reviewing, using ICT, logistics

partially realized: collaborative authoring

Effectiveness: neutral. System was effective for peer review, logistics and experiencing groupware. Less effective for collaboration because of live contact and FTP-tools.

Ease of use: positive. Participants are young and very experienced computer users. System was perceived as easy to learn. Participants have easy access to networked computer.

Engagement: positive. Very experienced computer users. Willing to try out new technologies (is part of their study). Moreover, the use of ICT was related to the course topic.

Environment: positive. Organization with a very positive attitude towards ICT and good facilities and infrastructure.

\subsection{Case 4: "ICT course"}

ICT course for teachers, Noordelijke Hogeschool Leeuwarden, 1998/99 (Gommer 1999)

The last UT case mentioned here is an ICT course for teachers in higher education. The course was given on-site at a university of professional education in Leeuwarden by instructors of the educational centre of the University of Twente. In this course, teachers were working together in groups on a design for implementing ICT in one of their own courses. In six course sessions of one day, course participants attended lectures about ICT in education and worked on their products in groups, supported by two instructors from the educational centre. In between course days, the course participants were supposed to work on their products too, with the possibility to receive technical and educational support from the instructors through e-mail or BSCW.

During the course, a course website and BSCW were used to let the teachers experience the use of ICT in education themselves. The goal was to let the groups work together in BSCW on their product and to give groups access to the workspaces of the other groups in order to learn from each other, share ideas and comment on each others' products.

Intended use: collaborative authoring, reviewing, using ICT

By most groups, BSCW was rarely used after the training session. The groups chose to carry their products around on disks and hand in assignments to the instructors on paper or by e-mail. One or two groups decided to put their products in BSCW, but since other groups didn't, there weren't many interesting things for them to see in the other workspaces. Because most teachers only worked with BSCW at the training session, they did not really experience the benefits and drawbacks of working with a groupware tool.

Partially realized: using ICT

not realized: collaborative authoring, reviewing 
Effectiveness: neutral. System could have been successful for peer review and experiencing groupware, but was not because of infrequent use.

Ease of use: negative. Group of participants consisted of both inexperienced and relatively experienced computer users. The system was not perceived as easy to learn. Participants did not have easy access to a networked computer.

Engagement: neutral. Both inexperienced and relatively experienced computer users, in an organization with a very neutral attitude towards ICT. Participants were interested in new technologies, but uncertain about their computer skills.

Environment: negative. Organization with neutral attitude towards ICT (just starting to innovate, little experience) and medium facilities and infrastructure.

4.5 Case 5: "Law and Informatics"

University of Amsterdam, 1997 (Groothuismink, 1998)

Law students of the University of Amsterdam are using BSCW for their group assignments. Each group places both product and process related information in their group workspace. Instructors can comment working plans and deliverables. A course folder contains course information and final deliverables of groups, so that these are accessible to other groups. Each student thus has access to two folders: one group archive and one course archive. Communication was also planned to take place via the workspaces.

Intended use: archiving, collaborative authoring, reviewing, monitoring, communication, course info

Students appreciated the flexibility of the website and the access to course related information. The instructors add that electronic communications have lowered the hierarchical distance between staff and students. The workload of the staff however increased due to the answering of e-mail messages. Technical problems reported relate to laborious user administration and poor server performance due to the fact that the server was also supporting other services at the same time. Students reported that they needed quite some time to learn the tool. Also the editing of documents and the successive uploading was experienced as difficult. If you want to change a document, quite some steps are needed before the edited document is back in the workspace. Moreover, students sometimes simply forgot to upload edited documents. It is counterintuitive that when you click on a document in the workspace, edit it, and save it, the new version is not in the workspace but on your local disk.

As far as communication is concerned, it turned out that e-mail was preferred, but the instructor and students also sometimes used the possibility to attach notes to documents.

The course related information will be back in a paper based handout, as most students printed these out.

Currently, the course is using Blackboard in combination with the course Web site.

Realized use: archiving, collaborative authoring, reviewing, course info partially realized: monitoring, communication

Effectiveness: neutral. Flexibility of access to the course-site was appreciated. BSCW was effective for archiving although students state that it is "not really necessary". For communication e-mail was preferred. Course materials will move from BSCW to hardcopy reader as many students started printing the materials themselves.

Ease of use: negative. Students report that it takes them quite some time to learn the tool. Also editing of documents in the workspace is laborious and the combination of systems involved does not convey a proper mental model of where a document is located.

Preparing student accounts and workspaces in advance is not easy for administrators.

Engagement: positive. The students are motivated to use the Internet. It is reported to be one of the reasons for choosing the course. The instructors are motivated as the course topic relates to the use of Internet within the domain of law. 
Environment: negative. The Faculty was not yet running a Web-server at the time. The instructor was supported by a technical support staff member. The first course using BSCW was hindered by some technical problems. Initially, the server was too slow. This improved after the BSCW server was moved to a different machine not used for other services.

\subsection{Case 6: "Pupil Counselling"}

Training course for teachers, Hogeschool van Utrecht (Koenraad, 1999)

A group of 25 students was involved in a course module on "Pupil Counselling \& Remedial Teaching". The module consists of a theoretical part and a practical period. During the practical period groups of three students are to work on assignments. Their deliverables were to be presented to their fellow students and instructors via BSCW. The students were expected to comment on the methods, results and presentation of other groups.

Sub-directories were prepared, some of these being used to enable access of course materials. A discussion directory also prepared as a platform for online communication.

Intended use: archiving, collaborative authoring, discussion, reviewing, course info.

The students were satisfied about their own sub-group way of working and product. Students reported that most of the task could be performed without much interaction with students in their own group, and even more without need for interaction with students in other groups. The peer commenting that was planned for did not work well. Some groups ignored this task, possibly because of not being aware that a certain deliverable was waiting for a review. Most students, all with no prior groupware experience, report the BSCW user interface to be unfriendly. Those groups favouring BSCW did use the system extensively in combination with e-mail for more prompting communication purposes.

Realised use: archiving, collaborative authoring, course info partially realized: discussion not realized: reviewing

Effectiveness: neutral. Group archiving worked well for the groups who used BSCW. Peer reviewing did not work well due to the fact that some groups ignored the system. Also the awareness of a peer-commenting task waiting to be performed was low. For communication e-mail was preferred. In remarks students reported to prefer live discussions about each others' products.

In the course evaluation the instructors noted that the interdependence of the students' tasks was not high, so there was no great need for regular communication.

Ease of use: negative. Students had an adequate level of general computer literacy (text processing, e-mail, Internet), but little or no prior experience with groupware tools. The students reported the user interface to be unfriendly. Also students reported problems with login procedures.

Engagement: neutral. The students showed a moderately positive attitude with respect to sharing expertise. In practice however they preferred to finish their tasks with few interactions with other students, in particular those from other groups. The instructors were eager to experience the potential of using groupware to support the groups. In hindsight they report that it was not clearly communicated to the students what was expected of them in their using BSCW.

Environment: neutral. It turned out that performance was a problem. Later on the course this could be improved, by moving BSCW to a faster server. 


\subsection{Case 7: "Software Engineering"}

University of Durham (UK), 1997/98, 1998/99 (Drummond and Boldyreff, 1999, 2000)

Software Engineering is essentially a team activity, hence the Computer Science staff at the University of Durham felt the need for a computer infrastructure to support team work in their courses. This was implemented in an environment, called SEGWorld, which is essentially a BSCW server with a few enhancements. The course has been given from 1997 onwards, evaluations for 1997/98 and 1998/99 have been consulted for this study (Drummond and Boldyreff, 1999, 2000). The environment continues to be used.

The system serves as an infrastructure for keeping group work organized. At the various deliverable deadlines the assignments are automatically copied form the groups' workspaces. So it serves both to share documents in the group and to hand in the results. The student groups also review each other's deliverables at various points throughout the year. For example, the requirements deliverables are all reviewed using the workspace and the reviews are uploaded to the workspace for rating. Course information about the SE course (and others) is also held in the SEGWorld environment.

Intended use: archiving, collaborative authoring, reviewing, communication, using ICT, course info, access control

In the first course there were some technical problem with the system, and the server was rather slow, which impeded the use of the system. Also, due to various reasons, the initial training of the students was not felt to be adequate. The system was used for storing the results (this was obligatory). In a questionnaire, $50 \%$ of the students said the system helped to organize the work , $65 \%$ indicated that the workspace structure was useful. Only $2 \%$ said the system resulted in better communication with the tutor and the group. (This was not stated as an aim for the course). In the second year, these figures were $68 \%, 82 \%$ and $12 \%$, respectively.

A daily log summary of the workspace was generated using BSCW's "workspace report" feature (notification by email of events in the workspace), primarily with the purpose of gathering statistical data. This yielded another - unanticipated - benefit: it provided the tutors with some insights into the contributions of the individual students with the group and more generally gave a means of assessing a group's progress.

Realized use: archiving, using ICT, reviewing, course info, access control unanticipated use: monitoring partially realized: collaborative authoring, communication

Effectiveness: Positive for storing documents early in the life cycle (requirements specification and design) but not suitable for maintaining source code, which consisted of a large number of different modules. Not effective for communication, because groups met regularly face-toface with their tutors.

Ease of Use: generally OK, the students were computer literate.

Engagement: Generally positive.

Environment: Slow response times were perceived as a problem. For that reason, some users moved the group work to a UNIX server for day-to-day use. 


\section{Cross-case comparison}

In Table 2 the results of the case studies discussed in section 4 are summarized. We will first examine the educational functions across the different cases and subsequently analyse these results in the light of the $4 \mathrm{E}$ model.

\begin{tabular}{|c|c|c|c|c|c|c|c|c|c|c|}
\hline & \multirow{2}{*}{$\begin{array}{c}1 \\
\text { Educ- } \\
\text { ational } \\
\text { training }\end{array}$} & \multirow{2}{*}{$\begin{array}{l}\text { Design } \\
\text { project }\end{array}$} & \multirow{2}{*}{$\begin{array}{l}\text { CScW } \\
\text { course }\end{array}$} & \multirow{2}{*}{$\begin{array}{c}\text { ICT } \\
\text { course }\end{array}$} & \multirow{2}{*}{$\begin{array}{c}5 \\
\text { Law \& } \\
\text { Inform- } \\
\text { atics }\end{array}$} & \multirow{2}{*}{$\begin{array}{c}6 \\
\text { Pupil } \\
\text { couns- } \\
\text { elling }\end{array}$} & \multirow{2}{*}{$\begin{array}{c}7 \\
\text { Softw. } \\
\text { Engin- } \\
\text { eering }\end{array}$} & \multicolumn{3}{|c|}{$\begin{array}{l}\text { Success / } \\
\text { failure: }\end{array}$} \\
\hline & & & & & & & & + & $+/-$ & - \\
\hline a. Archiving & + & + & + & & + & + & + & 6 & & \\
\hline b. Coll. authoring & - & + & $+/-$ & - & + & + & $+/-$ & 3 & 2 & 2 \\
\hline c. Discussion & - & & & & & $+/-$ & & & 1 & 1 \\
\hline d. Reviewing & + & & + & - & + & - & + & 4 & & 2 \\
\hline e. Monitoring & + & & & & $+/-$ & & + & 2 & 1 & \\
\hline f. Communication & - & $+/-$ & & & $+/-$ & & $+/-$ & & 3 & 1 \\
\hline g. Using ICT & + & & + & $+/-$ & & & + & 3 & 1 & \\
\hline h. Logistics & & & + & & & & & 1 & & \\
\hline i. Course info & + & & & & + & + & + & 4 & & \\
\hline $\mathrm{j}$ : Access control & + & & & & & & + & 2 & & \\
\hline & $=$ succes & fful use & $+/-=$ & eutral & $-=$ uns & iccessfu & use & & & \\
\hline E1 (effectiveness) & - & + & $+/-$ & $+/-$ & $+/-$ & $+/-$ & $+/-$ & & & \\
\hline E2 (ease of use) & $+/-$ & + & + & - & - & - & + & & & \\
\hline E3 (engagement) & $+/-$ & + & + & $+/-$ & + & $+/-$ & + & & & \\
\hline E4 (environment) & + & + & + & - & - & $+/-$ & $+/-$ & & & \\
\hline Sum: & $+/-$ & + & + & - & $+/-$ & $+/-$ & + & & & \\
\hline & $=$ positi & $+/-$ & neutral & $-=1$ & gative & & & & & \\
\hline
\end{tabular}

Table 2: cross comparison of cases

\subsection{Educational functions}

The table shows that some functions are used more than others. It should be noted that no statistical significance can be attributed to that, as the sample has not been selected to be representative in this respect. We recall that the sample has been chosen from a larger survey because the cases involved show qualitative differences in type of usage and acceptance. What is relevant in this table, however, is to uncover possible reasons why certain functions are successful in some case and fail in other cases. 
Archiving is used in all cases but one, and is always reported to be a success (although not always a $100 \%$ success; occasionally groups didn't use it). Archiving is the core function offered by the BSCW system, so it can be expected to be particularly suitable for that purpose, and it does not come as a surprise that this function is generally accepted.

Collaborative authoring was intended to be used in all cases, with rather different results. The following reasons emerged for not using BSCW for collaborative authoring. In the educational training (1) and the CSCW course (3), the students regularly met face to face, and saw no reason to put collaborative work into a workspace. In the Software Engineering course, the system was rather slow and the students, all having access to the same local network, used a UNIX directory because of its better performance.

In case 4, the ICT course, the breakdown was caused by environmental factors. The participants were motivated to learn about ICT, but not very experienced with it. The participants were teachers who did this on top of their (considerable) normal work load. So when it came to doing homework, it was too tempting to revert to proven methods known to work.

Discussion was not really successful anywhere. Both cases in which it was intended to be used suffered from the same flaws. It was not effective in the sense that participating in a discussion was not a learning aim of the course and, moreover, there were enough possibilities for live interaction for those who wanted to engage in further discussion.

Reviewing worked well in four out of six cases. Failures occurred the ICT course (generally unsuccessful), in which looking at other work of other groups failed because there was hardly anything in the workspace and case 6, pupil counselling, where participants did not do it, perhaps because they did not notice there was material to be reviewed.

Monitoring shows different results. Manual inspection, i.e., monitoring by browsing through the workspaces is (rightly) perceived as tedious. A basis for more systematic monitoring is provided by the daily notification emails provided by the server, as the Software Engineering course successfully demonstrated.

Communication was nowhere really successful, apparently because there are more effective ways to communicate, such as email. Noteworthy in the Law \& Informatics course is that the use of a workspace resulted in more communication between students and teachers and led to an increase in the use of email. BSCW was used as a communication medium only to a limited extent, but the use of BSCW lowered the threshold to communicate with teachers through email.

Course information disseminated through a shared workspace does work, in the sense that people will pick it up. Interestingly, in one of the cases reported, it was decided to revert to paper the next year, so as to prevent that everybody has to print it. We conclude that is should not replace the course manual but only be used for information of a more volatile nature.

The password protection of a workspace makes it possible to put course material online that one would not like to make publicly available on the Web.

Using ICT was mentioned as an objective four times, and reported to be successful three times. The table confirms previous findings (Sikkel and van Veen, 1998) that the objective to use ICT is successful only if the ICT is used for some sensible purpose in the course. To ask people to use an ICT system when it is not effective for the course objectives (excluding using ICT as a goal in itself), does not work. A surplus of engagement may induce a single user to thoroughly explore the system, for group work it cannot compensate zero or negative effectiveness, because the critical mass for success - which is full participation with a working group - is never reached (Dix, 1997, Grudin, 1988). On the other hand, if the use of ICT appears to be an effective way to fulfill the tasks related to the course, and there are no serious breakdowns in the other $3 \mathrm{E}$ 's, it will be naturally accepted. 


\subsection{Application of the 4E model}

The 4E model gives an indication of the acceptance of ICT. ICT will be used only if the sum of the four vectors exceeds a certain threshold. In this comparison we used the model giving qualitative indications for each of the four dimensions for the different cases. Indeed it is hard, if not impossible, to attribute quantities to these dimensions, and for the purpose of this study it is not necessary to do so.

Some educational functions appear to be generally successful (e.g. archiving) while others are generally not very successful (e.g. communication). Interesting in this context are the functions that are successfully used in some cases and failed in others. It is to be expected that there is a correlation with the "sum vector", i.e. the overall assessment, of the 4E model. For example, use of ICT as a goal in itself should be strongly correlated to the 4E sum. The single case in Table 2 in which use of ICT was not marked successful seems to confirm this.

Interesting functions in this respect are the following.

- Reviewing lists 4 successes (with $4 \mathrm{E}$ sum:,,,$+++-+/-$ ) and 2 failures (with $4 \mathrm{E}$ sums $+/-,-$ ) This confirms the expectations.

- Collaborative authoring lists 3 successes (4E sums,$++/-,+/-), 2$ neutral $(+,+)$, and 2 failures $(+/-,-)$. Remarkable is that cases in which collaborative authoring was neutral had a better $4 \mathrm{E}$ assessment than some in which it was a success. This seems to contradict the above stated assumption an merits a closer investigation.

In the CSCW course (case 3), collaborative authoring was en essential part of the course, but not an essential element of BSCW usage in the course. The functionality was available, if needed, but apparently most groups preferred other means of collaboration and only put the deliverables into the workspace.

Similarly, in the SE course (case 7), a number of groups reverted to using a UNIX server, which, in the specific circumstances (large number of files, BSCW performance problems, all group member on the same LAN) was simply more efficient.

Interestingly, both cases took place in ICT-rich environments, in which different platforms and systems can be used for the same function. Groups that work in physical proximity in an ICTrich environment do not seem to need a special tool for collaborative authoring. The collaborative authoring was performed as required, but with other means.

Note that in the design project (case 2), which took place in an environment with similar technological characteristics, the groups were more distributed and did find a shared workspace useful for collaborative authoring.

Note, furthermore, that the use of BSCW as a tool for collaborative authoring was also accepted more naturally in an environment where ICT is not ubiquitous but specially provided for this purpose (cases 5 and 6 ). The relative effectiveness of a tool is enhanced by lack of alternatives for the same function.

We conclude that an ICT-rich environment may lead to easier acceptance of a tool, but also increases the chance that the tool provided by the course instructors is abandoned in favour of a more efficient tool that is readily available.

This conclusion does not invalidate the $4 \mathrm{E}$ model, because it is very specific for the tool that is the subject of this study. 


\section{Analysis and conclusion}

The purpose of this study is to discuss the effectiveness of one particular tool, a BSCW shared workspace, for different educational functions. The $4 \mathrm{E}$ model provides a relevant context for such a discussion. It shows us that effectiveness is only one of the four dimensions that are important for predicting the success of an ICT application in education. The application of a system is likely to fail when the effectiveness of a system does not outweigh negative aspects related to ease of use, engagement of the students and environmental (organisational, social-cultural and technical) factors. This most important observation should be kept in mind in the design and planning of ICT-supported courses. The comparison of the seven case studies in Table 2 illustrates this.

Having said this, we will focus on the issues we set out to investigate, the suitability of a (BSCW) shared workspace for different educational functions. We will be primarily concerned with the first $E$, effectiveness, and to a certain extent with efficiency, which constitutes one of the factors grouped into Ease of use. The 4E model tells us that these are important factors, but cannot (nor is intended to) help us in a deeper analysis of when a tool is effective for a particular purpose. Comparing the use of BSCW across a series of case studies does shed some light on the effectiveness of shared workspaces in an educational setting.

\subsection{Educational functions revisited}

Based on the discussion in Section 5 we make the following observations

- Archiving was used a lot and turned out to be generally successful. This is hardly surprising, because it is one of the core functions of the BSCW system and hence a function for which it this tool is particularly suitable.

- BSCW is an effective tool for collaborative authoring, but not necessarily the most efficient tool. When students meets face to face on a regular basis, or when the objects of collaborative work reside in a network to which the whole group has access, it is not perceived as efficient to put the shared work into a shared workspace.

Furthermore, when the use of ICT is generally problematic (as in the ICT course, case 4) this reduces the effectiveness. In group work, a tool is effective only if it is accepted by everybody in the group (Grudin, 1988).

Some computer literacy in terms of using a PC and the Internet is needed to meet the technical and organisational preconditions for collaborative authoring. To the computer illiterate, BSCW does not convey a suitable mental model of where documents reside and proper instruction is required.

In an ICT-rich environment supporting multiple ways of collaboration a shared workspace is effective for collaborative authoring, but it need not be the most efficient way, depending on the task, the nature of the shared objects, and the distributedness of the group.

These things should be kept in mind when BSCW is planned to be used for collaborative authoring. It seems advisable to offer it as a resource that can be used, but leave collaborating authors the freedom to use other means available and more readily applicable. When the course instructors want to inspect intermediate products (for example to monitor progress) these can be requested as separate deliverables.

- The success of using BSCW to review each other's work appears to be linked to the general success of using BSCW in a course. Presumably it is also related to the specific course setup, which products are to be reviewed by whom, and what is the purpose of reviewing in the particular course. If the other conditions are satisfied, shared workspaces are an effective tool for reviewing.

- In several cases BSCW was intended to be used for communication, but nowhere this was really a success. With hindsight (always a lot easier) it is obvious that email is a more effective communication medium. A form of communication where the lack of obtrusiveness provided by BSCW is an advantage is handing in assignments. These need no immediate 
response, can be collected from the workspace after the deadline, and do not clutter up the instructors' private mailboxes.

From CSCW research it is known that collaboration involves communication on two levels: exchange of the objects of collaborative work as well as discussion about these objects (Robinson, 1991). From this perspective it seems reasonable to use a workspace as the medium for storing objects of collaboration, while email is used for the meta-level communication. In a normal computer-based working environment, both media are present.

- Monitoring students' progress can be based on the data provided by BSCW. However, the raw data are of little help. least of all browsing a workspace to see whether students make progress. If monitoring is intended, some additional processing of raw data is to be implemented locally.

- We are sceptical about the use of structured discussions in courses. Both cases in this study were flawed in the sense that participating in an online discussion was neither a learning aim of the course nor an effective way to discuss. Other experiences seem to confirm this. Jones (1999) reports about a case where taking part in an online discussion was one of the formal requirements for a course. The most efficient way to meet this requirement, it turned out, was to meet in the lab, have a face-to-face discussion there, and fake into an online discussion.

We suspect that online discussion facilities are offered as part of an experimental ICT courses mostly because the technology is available, ready to be used. Without doubt there are circumstances where an online discussion platform is a valuable asset, but this is not the case if it is used as an add-on to a traditional course ported to an ICT environment.

Anybody considering using this feature should be very clear about its purpose, as well as the effectiveness and the efficiency of the ICT tool offered.

\subsection{Effectiveness}

There are two kinds of reasons why the effectiveness of tool for an educational application can be problematic.

Firstly, and most obviously, if there are more effective ways, whether ICT-related or not, to fulfill a particular task, students are naturally - and rightly - inclined to opt for the more effective solution. An example of lack of effectiveness is when BSCW is used as a communication medium, but the intended recipient is not aware that he should collect something from the workspace.

A second source of effectiveness failure is that the chosen tool is effective for the particular activity, but the planned activity is not effective for reaching the overall objectives of a course. In particular when the use of ICT is a goal per se, it is tempting to plan these kind of activities. This is illustrated with the online discussion function discussed above.

One aspect that we have not explicitly discussed is the ease or difficulty in bringing the course participants in face-to-face contact. One of the purposes of groupware in general, and shared workspaces in particular, is to provide an effective substitute when a group has few or no possibilities to come together. It has been claimed that the use of shared workspaces reduces the need for face-to-face session. (Vliem, 1996; Sikkel and van der Veen, 1998). From this study we can learn that this claim is subject to the $4 \mathrm{E}$ model. The set-up of the both the educational training and the ICT course (cases 1 and 3) were designed to exploit the fact that course participants could cooperate in between course sessions. The former case was only a partial success due to problems in effectiveness, the latter case rather unsuccessful because of environmental problems and negative ease of use.

\subsection{Efficiency}

Similar to effectiveness, students, like being efficient. If there is a more efficient way to fulfill a task than using the groupware provided by the course instructors, students will do it the efficient way (unless there is a formal obligation to do so, but this does not have a beneficial effect on 
Engagement). An example of non-efficiency is using a BSCW server with performance problems for collaborative authoring when everybody has access to the common file server. Potential advantages of BSCW over FTP are (justifiably) given less weight than the immediate frustration resulting from a server that is too slow.

On a more general level, there is often a tacit assumption that cooperation is needed in order to perform a task. If group task can be solved effectively by dividing it into separate subtasks, this is likely to be more efficient as well. If it is intended that the groupware be used as groupware, then the task given to a group of students should make it necessary to share ideas and results arising from different subtasks. Otherwise it is more efficient not to use it. Case 6, pupil counselling, had this problem to some extent. At the University of Twente we have also learnt this from experiences with earlier ICT-based courses.

\subsection{Conclusion}

In the current state of the art there are no infallible truths and definite answers, and much valuable knowledge and insights still come in the 'lessons learnt' style of observations. With our evaluation method, an ex post qualitative study of a number of applications in different settings, we can compare the lessons learnt from different courses under different circumstances and obtain findings of a somewhat more general nature. While it is obvious that further empirical analysis is needed for the issues raised here, we hope at least to have contributed to a deeper insight into which issues do merit such a further analysis.

A general observation is that the 4E model of Collis et al., which states that Effectiveness, Ease of use, Engagement and Environment are equally important for the success of an ICT application, does apply to the cases in this study. No matter how effective a system is, serious problems in the other factors may cause a system to fail nevertheless.

The general conclusion of this study is that the particular strength of a shared workspace, not surprisingly, is what can be considered as it's core functionality: providing a repository for objects of collaborative work. Using a shared workspace as an archive was successful in all cases.

The BSCW system, originally designed as a basic shared workspace system, provides a number of additional facilities that could support the collaboration process. In various educational settings, course instructors have tried to use BSCW for an equally varied range of educational functions, with more or less success, depending on the situation as discussed above. One of the reasons could have been that for a given course a single system (BSCW) was chosen for ICT support, and it has been tried to exploit this particular system for multiple purposes.

In the future we expect that learning takes place in an integrated, open ICT environment in which different kinds of tools are available for different purposes and users can switch between tools as appropriate. We could observe this in several of the case studies, where non-use of BSCW did not mean that a particular task was not performed, but, on the contrary, a more efficient solution for the same function was available. Shared workspaces have proven to be highly useful, but it seems advisable that their purpose be limited to what they were originally designed for.

\section{Acknowledgements}

We are grateful to Cornelia Boldyreff, Betty Collis, Sarah Drummond, Michiel van Geloven, Elly Govers, Ton Koenraad, and Radboud Winkels for constructive comments on a draft version. 


\section{References}

Bentley, R., T. Horstmann, K. Sikkel and J. Trevor (1995). Supporting collaborative information sharing with the World-Wide Web: The BSCW Shared Workspace system. Proc. 4th international WWW conference, Boston, Mass., pp. 63-73

Bentley, R., W. Appelt, U. Busbach, E. Hinrichs, D. Kerr, K. Sikkel, J. Trevor and G. Woetzel (1997). Basic support for cooperative work on the World Wide Web.International Journal of Human-Computer Studies Vol. 46, pp. 827-846.

Collis, B. and N. Pals (1999). A Model for Predicting an Individual's Use of a Telematics Application for a Learning-Related Purpose. International Journal of Educational Telecommunications, 6(1) pp. 63-103.

Collis, B., O. Peters, and N. Pals (2000). Influences on the educational use of the WWW, email and videoconferencing. Innovations in Education and Training International, 37(2), 108-119.

Collis, B., O. Peters, and N. Pals (in press). A Model for Predicting the Educational Use of Information and Communication Technologies. Instructional Science.

Dix, A. (1997). Challenges and Perspectives for Cooperative Work on the Web: An Analytical Approach. Computer Supported Cooperative Work: The Journal of Collaborative Computing, Vol. 6, pp. 135-156.

Drummond, S. and C. Boldyreff (1999). SEGWorld: A WWW-based Inforastructure to Support the Development of Shared Software Engineering Artifacts. Workshop on Web-Based Infrastructures and Coordination Architectures for Collaborative Enterprises, IEEE $8^{\text {th }}$ Int. Workshop on Enabling Technologies: Infrastructure for Collaborative Enterprises (WET-ICE'99).

Drummond, S. and C. Boldyreff (2000). The Development and Trial of SEGWorld: A Virtual Environment for Software Engineering Student Group Work" (1999) IEEE $13^{\text {th }}$ Conference on Software Engineering Education and Training (CSEE\&T 2000) Austin, Texas, USA, pp. 87 -97

Gommer, E.M. (1999). Eindrapport Evaluatie BSCW. OC-Doc 99-10, Onderwijskundig Centrum, Universiteit Twente.

Groothuismink, J. (1998). Het gebruik van groupware door samenwerkende studenten. In: Internet \& Onderwijs, 9 voorbeelden van Internettoepeassingen in het wetenschappelijk onderwijs, Universiteit van Amsterdam

Grudin, J. (1988). Why CSCW applications fail: Problems in the design and evaluation of organizational interfaces. Proc. Conf. on Computer-Supported Cooperative Work (CSCW'88), Portland, Oregon, 8593.

Jones, C. (1999). Cooperating to collaborate: Course delivery using computer conferencing in higher education. In A. Eurelings et al. (Eds.), Integrating Information and Communication Technology in Higher Education, Kluwer, Deventer, pp.247-269.

Koenraad, A.L.M. (1999). Groupware ter ondersteuning van samenwerken en samenwerkend leren. Proceedings Nederlands Informatica Onderwijs Congres (NIOC'99), Enschede, Netherlands.

Robinson, M. (1991). Double-Level Languages and Co-operative Working. Al and Society, Vol. 5, pp. 3460.

Sikkel, K. and J. van der Veen (1998). Using Shared Workspaces in Higher Education. Unpublished draft, Faculty of Computer Science, University of Twente, Enschede, the Netherlands. http://wwwhome.cs.utwente.nl/ sikkel/papers/other/bite98.ps.gz

van der Veen, J.T., V. Jones, and B.A. Collis (2000). 'Theory Repositories' via the Web for Problem-Based Learning. To appear in Journal of Interactive Learning Environments, Swets \& Zeitlinger, Lisse, the Netherlands.

Vliem, M.E. (1997) Using the Internet in university education - The application of BSCW within student projects, Internal report, Ergonomics Group, University of Twente, Enschede. http://bscw.gmd.de/Papers/Uni-Twente/BSCWEval.ps

Yin, R.K. (1994). Case Study Research: Design and Methods. Second edition. Sage publications, London. 